\title{
DÜBLIN
}

Technological University Dublin

ARROW@TU Dublin

\section{Modelling the Effects of Natural Antimicrobials as Food Preservatives}

\author{
Amit Jaiswal \\ Technological University Dublin, amit.jaiswal@tudublin.ie \\ Swarna Jaiswal \\ Technological University Dublin, swarna.jaiswal@tudublin.ie
}

Follow this and additional works at: https://arrow.tudublin.ie/schfsehbk

Part of the Food Microbiology Commons

\section{Recommended Citation}

Jaiswal, A. K. \& Jaiswal, S. (2014). Modelling the effects of natural antimicrobials as food preservatives. In: Taylor M. (ed. ) Handbook of Natural Antimicrobials for Food Safety and Quality. (pp. 259-284).

Woodhead Publishing Limited, Cambridge, UK. doi:10.1016/B978-1-78242-034-7.00012-8

This Book Chapter is brought to you for free and open access by the School of Food Science and Environmental Health at ARROW@TU Dublin. It has been accepted for inclusion in Books/Book Chapters/ Proceedings by an authorized administrator of ARROW@TU Dublin. For more information, please contact arrow.admin@tudublin.ie, aisling.coyne@tudublin.ie, gerard.connolly@tudublin.ie.

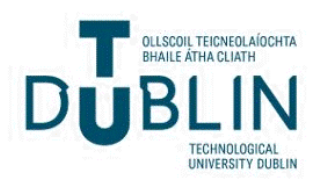




\title{
14 Modelling the effects of natural antimicrobials as food preservatives
}

\section{Amit Kumar Jaiswal $^{1 *}$ and Swarna Jaiswal ${ }^{2}$}

${ }^{1}$ School of Food Science and Environmental Health, Dublin Institute of Technology, Dublin 1, Ireland

E-mail: amit.jaiswal@dit.ie

${ }^{2}$ Centre for Research in Engineering Surface Technology (CREST), FOCAS Institute, Dublin Institute of Technology, Dublin 8, Ireland

E-mail: swarna.jaiswal@ dit.ie

\begin{abstract}
A predictive food microbiological model is a mathematical representation of mechanisms that describes the growth, survival, inactivation or biochemical process of an organism and are used in the food industry to predict food pathogen growth and to help in the evaluation of food safety. Furthermore, it reduces the number of expensive and time-consuming experiments; however, adequate statistical analysis is a crucial step during all phases of model development and validation. Therefore, present chapter is focused on the basic concept of mathematical modelling which can be applied to estimate the effects of natural antimicrobials as food preservatives. Initial section discusses about the importance of modelling in food preservation, brief introduction to types of modelling, model development and validation and the final section includes review of recent research in natural antimicrobials modelling.
\end{abstract}

Key words: Food preservatives; Gompertz model; growth curve; mathematical models; natural antimicrobials 


\subsection{Introduction}

Food products are perishable by nature and require protection from spoilage during their preparation, storage and distribution to give them desired shelf life. Spoilage or other changes lead to loss of shelf life, which may occur in any stages of acquisition of raw materials and the eventual consumption of the finished products. The principal reactions that lead to spoilage, and that are therefore, also the principal targets for effective preservation and control, includes physical, chemical, enzymatic and microbiological factors. Because food products are now often sold in areas of the world far remote from their production sites, the need for extended safe shelf-life for these products has also expanded. Improvements in the cold distribution chain have made international trade of perishable foods possible, but refrigeration alone cannot assure the quality and safety of all perishable foods (Holley and Patel, 2005).

The safety and quality of foodstuffs are paramount for consumer health and satisfaction. Preservatives are required to maintain the quality, extend shelf life, and ensure safety of food products. Recent regulations by the FDA have required processors to achieve a 5 log reduction in the numbers of the most resistant pathogens in their finished products. Therefore, most of the preservation techniques aim to control all the forms of spoilage. Synthetic preservatives form an essential part in food preservation. Chemicals such as butylated hydroxytoluene, butylated hydroxyanisole, sodium benzoate, sodium nitrite and potassium sorbate have been commonly used in food products. Recent research confirmed that synthetic preservatives are associated with some side effects (Botterweck et al., 2000); therefore, legislation has restricted their use in different foods (Brul and Coote, 1999). Furthermore, consumer preferences are moving towards foods that contain lower levels of chemical preservatives, exhibit characteristics of fresh or natural products and are microbiologically safe. 
Application of heat is the most common method for food preservation, because of its ability to inactivate microorganisms and spoilage enzymes. However, no matter how minimal the heating source is, thermal processing can promote reactions that could affect overall quality of foods. Today, the demand for processed foods goes beyond the fundamental requirements of safety and shelf-stability. More emphasis is being placed on high-quality and value-added foods. Nonthermal methods such as addition of natural antimicrobial agents in food, high pressure processing, ultrasound, ozone, pulsed electric field, and ultraviolet is increasingly gaining attention for food preservation. However, in recent years, the use of plant-derived naturally occurring antimicrobial agents to inhibit pathogen growth and prevent food spoilage has received special attention (Hayes et al., 2010). These compounds are naturally produced and isolated from various sources, including plants, animals and microorganisms, in which they constitute part of their host defence system (Juneja et al., 2012). Many naturally occurring compounds, such as polyphenols, glucosinolates, nisin and plant essential oils have been widely studied and are reported to be effective in their potential role as antimicrobial agents against spoilage and pathogenic microorganisms (Cleveland et al., 2001; Daglia, 2012; Jaiswal et al., 2011b; Solórzano-Santos and Miranda-Novales, 2012).

\subsection{Antimicrobial susceptibility assessment}

The antibacterial susceptibility test is used to determine the efficacy of potential natural antimicrobials against different bacterial species. However, one should keep in mind that antimicrobial susceptibility tests should be easy to do, reproducible (i.e. the ability to yield the same result on repeat testing), sensitive and specific (Lambert and Pearson, 2000). The usefulness of an antibacterial agent in combating food spoilage can be assessed by determining non-inhibitory concentration (NIC), the concentration above which the inhibitor begins to have a negative effect on growth, and the minimum inhibitory concentration (MIC), i.e. the 
minimum dose of the antibacterial agent required to inhibit the growth of the test bacterium as compared to control (Jaiswal et al., 2013; Lambert and Pearson, 2000; Tiwari et al., 2009). However, MIC and NIC value of an antibacterial agent is dependent on experimental conditions which includes the incubation temperature, type of organism, and inoculum size (Lambert and Pearson, 2000; Lambert and Lambert, 2003). The standard antibacterial susceptibility test can be conveniently divided into qualitative (diffusion) and quantitative (dilution) methods. Common diffusion tests include agar well diffusion and where target organisms embedded in an agar plate exposed to antibacterial agent using impregnated sterile disks of filter paper, or by placing the antibacterial agent directly on the surface or into preformed wells (Álvarez-Fernández et al., 2013; Kim et al., 2013; Vásconez et al., 2009). After an appropriate period of exposure (18-24 hours), the size of the zone of growth inhibition around the antibacterial delivery area is measured and considered as the indicator of antibacterial effectiveness. However, the agar diffusion assay is costly, time consuming, and the measurements tend to be more qualitative than quantitative. Dilution methods include agar dilution and broth micro/macro-dilution which reduces time and costs, and increase sensitivity for detection of antibacterial activity. However, most of these evaluations are based on only one endpoint and does not reflect the time-killing process.

\subsection{Mathematical modelling in food preservation}

A predictive food microbiological model is a mathematical expression that describes the growth, survival, inactivation or biochemical process of the foodborne organisms (GonzalesBarron, 2011). It is based on the fact that the responses of the micro-organisms to environmental factors are reproducible and that, by characterizing environments in terms of these factors. It is possible from past observation to forecast the responses of microorganisms in other similar environments; so, it can be useful to improve microbial food safety, quality and 
are leading to the development of a quantitative understanding of microbial ecology of foods. While mathematical models are very useful decision analysis tools, it must be remembered that models are, at best, only a simplified representation of reality (Fakruddin et al., 2011).

Traditional microbial enumeration techniques are time-consuming and therefore, mathematical microbial models are used to assess the potential for growth of micro-organisms in foods during preservation (Bovill et al., 2000) and can be very useful to reduce the number of expensive and time-consuming experiments. Furthermore, time-kill curve studies better describe the dynamic behaviour of antibacterial activity and from which a more accurate MIC value can be obtained (Andraud et al., 2011; Mueller et al., 2004). These curves are analysed using various mathematical models, usually based on the assumption that the relationship between antibacterial activity and antibacterial concentration has a sigmoid shape. Though, most of the modelling studies are primarily focused on the effect of temperature on growth and survival of bacterial or other factors, which have an impact on bacterial growth such as $\mathrm{pH}$, water activity, etc. and the data on the use of natural antibacterial agents for inhibiting microbial growth and modelling the resulting kinetics are not very common, and most of the studies are based on an endpoint MIC determination (Diao et al., 2013; Jordán et al., 2013). This chapter focuses on basic concept of mathematical modelling which can be applied to estimate the effects of natural antimicrobials as food preservatives.

\subsection{Types of models}

In the last few decades, several mathematical models are developed to estimate the growth or inactivation of microorganisms in food and subsequently several classifications were proposed. Models can be classified, by the microbiological event into kinetic and probability models (Roberts, 1989); Empirical and Mechanistic ways; or by the variables considered into primary, secondary and tertiary (Whiting and Buchanan, 1993). 


\subsubsection{Kinetic and probability models}

Kinetic model explains the time taken for a specified growth/death response, in terms of environmental variables such as temperature, $\mathrm{pH}$ (Boekel, 1996) or relative humidity, nutrient content and antimicrobial properties. Kinetic models are useful in that they can be useful to predict changes in microbial counts with time. Typical example of a kinetic model includes the Gompertz and square root models which, describe the rates of response, such as specific growth rate, lag time, and maximum population density (McMeekin et al., 1993; Whiting and Buchanan, 1994) or inactivation/ survival models that describe destruction or survival over time (Xiong et al., 1999). It also includes polynomial models based on surface response methodology where experiments generally involved simultaneous estimation of the effect of several factors on microbial growth or death.

Probability models take advantage of the possibility that a particular event will occur under specific environments. For example, it can be used to model spore forming bacteria such as a probability of Clostridium botulinum survival in canned corned beef (Buchanan, 1993). The basis for probability modelling is the relationship between the growth of microbial cells and the physico-chemical properties of the environment (Ross and McMeekin, 1995). Probability models specify only the probability of growth or toxin production and do not show the rate at which they occur (Roberts, 1989).

\subsubsection{Empirical and mechanistic models}

Another classification of models is mechanistic (i.e, explanatory, 'white box', or deductive) or empirical (i.e, descriptive, observational, 'black box' or inductive).

Empirical models are data-driven and describe the interpretation without attempting to relate them to an underlying theory. Empirical models are concerned with practical consequence and simply describe data under experimental conditions in the form of a convenient mathematical 
relationship (Gibson and Hocking, 1997). Polynomial equations are the common empirical models. Empirical sigmoidal type models such as the modified Gompertz and Logistic models have been used for fitting bacterial growth (Gupta et al., 2012).

Mechanistic models are built up from theoretical bases and allow interpretation of the response in terms of known phenomena and processes (Krist et al., 1998). Mechanistic models are considered to be preferable than the empirical ones, as they usually contain fewer parameters, fit the data better and extrapolate more sensibly (Draper, 1988). Mechanistically derived models would be easier to develop further, as the quantity and quality of information from the analysed system increases and mechanistic models are inherently superior to empirical models (Van Impe et al., 1992; Van Impe et al., 1995; Zwietering et al., 1993). Semi-mechanistic model of Baranyi-Roberts have been used for fitting bacterial growth (Gupta et al., 2012).

\subsubsection{Primary, secondary and tertiary models}

Whiting and Buchanan (1993) proposed a three-level classification method described as primary, secondary and tertiary mathematical models. Among them, the concept of the primary model is fundamental for predictive food microbiology.

Primary mathematical models estimate the response of the microorganism with time to a single set of conditions. The response can either be direct or indirect measures of microbial population density or products of microbial metabolism. Basically, it is aimed at describing the kinetics of the process with a few parameters as possible, while being able to accurately define different stages of growth. When the increase in population was plotted against time, the resulting curve usually has four stages; early stationary phase or lag phase, acceleration phase or log phase, stationary phase and decline or death phase.

The objective of the primary model is to test the ability of a model to fit individual growth curves and estimates its various parameters. This then can generate information about the 
microorganisms under investigation, such as lag phase duration $(\lambda)$, generation time (GT), maximum population density $(\mathrm{Nmax})$ and exponential growth rate $(\mu \max )$ (Whiting and Buchanan, 1993; Whiting, 1995) (Figure 14.1).

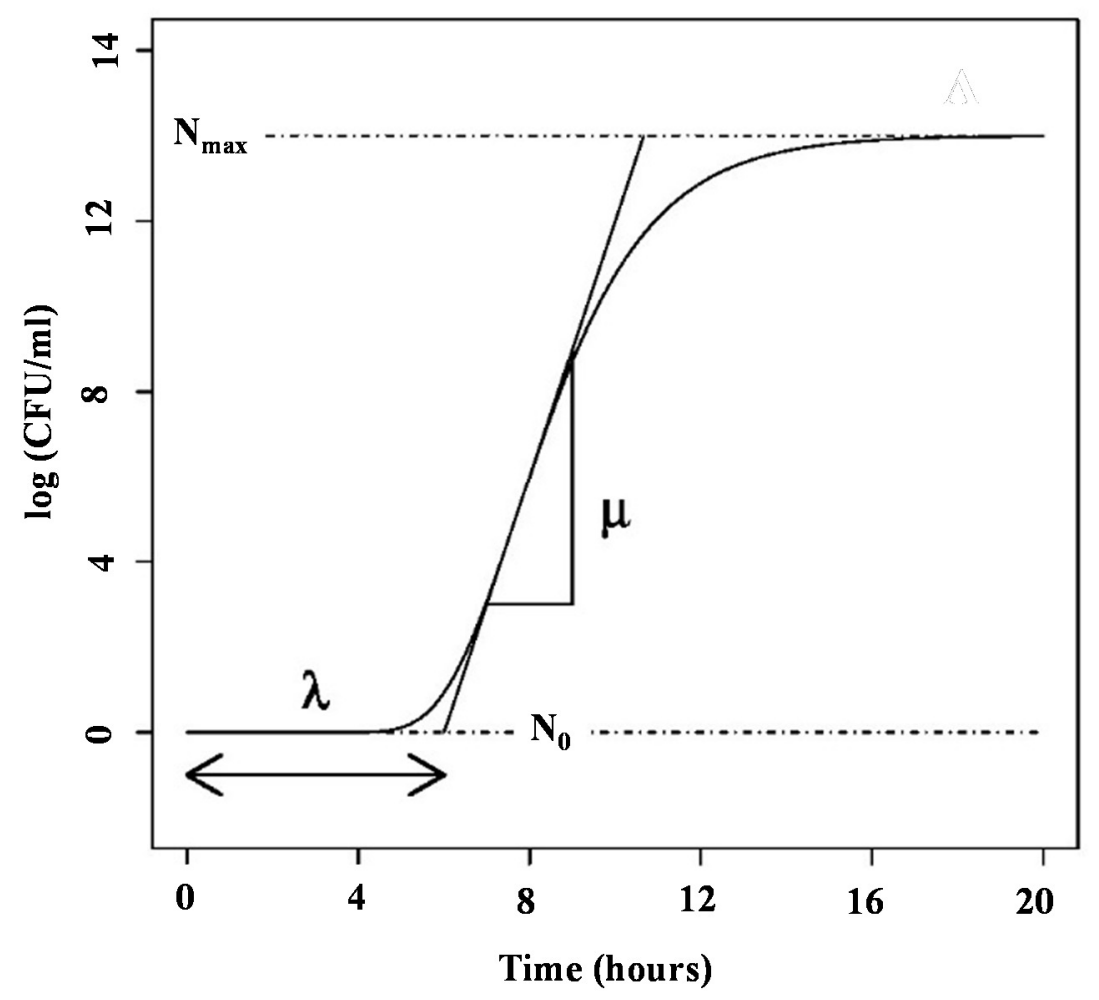

Figure 14.1. A typical growth curve and resulting parameters from the growth curves: lag phase duration $(\lambda)$, maximum population density $\left(\mathrm{N}_{\max }\right)$ and exponential growth rate $\left(\mu_{\max }\right)$. The integral (area under the curve) is also used as growth parameter (Adopted from Isabelle and André (2006)).

Generally, growth curves are figured on a $\log _{10}$ based cell density as a function of time, as microbial growth is an exponential phenomenon but sometimes a natural logarithm base is preferred. The exponential growth rate is defined as the steepest tangent to the exponential phase, so the tangent at the inflexion point, while the lag phase can be explained as the time at which that extrapolated tangent line crosses the inoculum level (McMeekin et al., 1993). The 
rate of exponential growth of a bacterial culture is expressed as generation time, also the doubling time of the bacterial population and can be calculated from $\mu_{\max }$ (eq. 14.1):

$$
\text { Generation time }(\mathrm{GT})=\frac{\log _{10} 2}{\mu_{\max }}
$$

First growth model was described by Monod and it was based on a pure empirical observation that bacteria grows exponentially.

$$
\mathrm{N}=N_{0} e^{k t}
$$

Where, $\mathrm{N}$ is the microbial density $(\mathrm{CFU} / \mathrm{ml}), \mathrm{N}_{0}$ is initial microbial population $(\mathrm{CFU} / \mathrm{ml}), \mathrm{K}$ is $\ln 2 / \mathrm{GT}\left(\mathrm{h}^{-1}\right)$ and $\mathrm{t}$ is time (h). However, it is limited as the only growth rate was considered for modelling and lag phase was also not modelled. Furthermore, important parameters such as maximum cell density was not taken into account.

Later, Gibson et al. (1987) introduced a non-linear Gompertz model and which make possible to express $\log (\mathrm{CFU} / \mathrm{ml})$ as a function of time using sigmoidal shape (eq. 14.3).

$$
\log N t=A+C \times \exp [-\exp [-\mathrm{B}(t-M)\}]
$$

Where, $N_{t}$ is the cell density at time $t, A$ is the lower asymptotic line of the growth curve as $t$ decreases to zero, $N_{0}$, initial population level at time $t=0(\log \mathrm{CFU} / \mathrm{ml}) ; C$, the difference between the upper asymptotic line of the growth curve (maximum population level, $N_{\max }$ ) minus the lower asymptotic line (for example, $\left.N_{\max }-N_{0}\right)(\log \mathrm{CFU} / \mathrm{ml}) ; B$, the relative maximum growth rate $\left(\mathrm{h}^{-1}\right)$ at time $M$; and $M$, the time at which the growth rate is maximum $\mu_{\max }\left(\mathrm{h}^{-1}\right)($ eq. 14.4) and lag phase duration $(\lambda, \mathrm{h})($ eq.14.5) can be calculated by the equations:

$$
\mu_{\max }=\frac{B \times C}{e}
$$


Where $\mathrm{e}=2.7182$

$$
\begin{gathered}
\lambda=M-\frac{1}{B} \\
N_{\max }=A+C
\end{gathered}
$$

In accordance with Gompertz model, a logistic model (eq. 14.7) was proposed by Gibson et al. (1987) to predict the microbial growth.

$$
N_{t}=A+\frac{C}{1+\exp [-B \times(t-M)]}
$$

where $N_{t}, A, B, M$, and $C$ have the same meaning as specified in Gompertz equation. The $\mu_{\max }$ (eq. 14.8) and $\lambda$ parameters (14.9) can be calculated as follows:

$$
\begin{aligned}
& \mu_{\max }=\frac{B \times C}{4} \\
& \lambda=M-\frac{2}{B}
\end{aligned}
$$

Model fitting results are similar in both the cases; however, Gompertz model was always preferred over the logistic model as the former is symmetrical models while most of the growth curves are not.

In 1990s, the focal point moved from the static primary model to dynamic primary models. Van Impe et al. (1992) proposed first-order differential equation to predict microbial growth and inactivation. A second dynamic growth model was proposed by Baranyi and Roberts (1994). The model was based on first-order ordinary differential equation and is one of the most frequently used differential equation models to predict microbial growth. It can be described as in (eq. 14.10): 
$\mathrm{y}(\mathrm{t})=\mathrm{y}_{0}+\mu_{\max } \mathrm{F}(\mathrm{t})-\ln \left(1+\frac{e^{\mu} \max ^{\mathrm{F}(\mathrm{t})}-1}{e^{y_{\max }-y_{0}}}\right)$

where, $\mathrm{F}(\mathrm{t})=\mathrm{t}+\frac{1}{v} \ln \left(e^{-v t}+e^{-h_{0}}-e^{-v t-h_{0}}\right)$

where $\mathrm{y}(\mathrm{t})$ is the $\log _{\mathrm{e}}\left(\mathrm{CFU} \mathrm{ml^{-1 }}\right)$ of cell concentration at time, $\mathrm{t}$; $\mathrm{y}_{0}$ is the initial cell concentration in $\log _{\mathrm{e}}\left(\mathrm{CFU} \mathrm{m} \mathrm{l}^{-1}\right)$ units; $\mathrm{y}_{\max }$ is the maximum cell concentration in $\log _{\mathrm{e}}(\mathrm{CFU}$ $\left.\mathrm{ml}^{-1}\right)$ units; $\mu_{\max }$ is the maximum specific growth rate in terms of $\log _{\mathrm{e}}\left(\mathrm{CFU} \mathrm{ml} \mathrm{m}^{-1}\right)$, which is equal to $r_{\max } \log _{\mathrm{e}} 10$ in $1 \mathrm{~h}^{-1}$; $\mathrm{v}$ is the rate of increase of the limiting substrate, assumed to be equal to $\mu_{\max }$; $\mathrm{h}_{0}$ is equal to $\mu_{\max } \times \lambda$; and $\lambda$ is the lag-phase duration in $\mathrm{h}$ (Baranyi et al., 1993). Table 14.1 summarizes most commonly used primary models that estimate the response of microorganisms.

Secondary mathematical models are produced from the primary model parameters such as lag time, growth/inactivation rate, maximum population density. It indicates that how parameters of the primary models change with respect to one or more environmental or cultural factors such as atmosphere, $\mathrm{pH}$, temperature; antimicrobial agent concentration applied and salt level. For example, if the effects of antimicrobial agent on the growth of microorganisms were being investigated, the organism would be grown at a number of antimicrobial concentrations for specific periods such as 24 to 72 hours. From each antimicrobial concentration, a generation time can be calculated by using a primary model. These data are then collated using a secondary model, so that the effect of antimicrobial concentrations is described by a mathematical equation. This allows the end user to determine what generation time will be observed at the respective antimicrobial concentrations. 
Table 14.1. Most commonly used primary, secondary and tertiary models used in the literature (Adopted and modified from McDonald and Sun (1999) with permission).

\begin{tabular}{|c|c|c|}
\hline Primary models & Secondary models & Tertiary models \\
\hline Gompertz model $^{1}$ & Williams-Landel Ferry model ${ }^{13}$ & USDA Pathogen Modelling Programme ${ }^{22}$ \\
\hline Modified Gompertz $^{2}$ & Belehradek model (square-root model) ${ }^{14}$ & Microfit software ${ }^{23}$ \\
\hline Logistic model ${ }^{3}$ & Ratkowsky model (square-root model) ${ }^{15}$ & $\begin{array}{l}\text { Seafood Spoilage and Safety Predictor } \\
\text { (SSSP) software }\end{array}$ \\
\hline Baranyi model $^{4}$ & Arrhenius model ${ }^{16}$ & ComBase $^{25}$ \\
\hline First-order monod model ${ }^{5}$ & $\begin{array}{l}\text { Modified Arrhenius models (Davey or } \\
\text { Schoolfield) }{ }^{17}\end{array}$ & \\
\hline Modified monod model ${ }^{6}$ & Probability models $^{18}$ & \\
\hline$D$ values of thermal inactivation ${ }^{7}$ & Artificial Neural Networks ${ }^{19}$ & \\
\hline Growth decline model of Whiting and Cygnarowicz ${ }^{8}$ & $Z$ values $^{20}$ & \\
\hline Three-phase linear model ${ }^{9}$ & Polynomial or response surface models ${ }^{21}$ & \\
\hline Richards model ${ }^{10}$ & & \\
\hline Schnute model ${ }^{11}$ & & \\
\hline Stannard model ${ }^{12}$ & & \\
\hline
\end{tabular}

${ }^{1}$ Gibson et al. (1987); ${ }^{2}$ Zwietering et al. (1990); ${ }^{3}$ Jason (1983); ${ }^{4}$ Baranyi et al. (1993); ${ }^{5}$ Monod (1949); ${ }^{6}$ Houtsma et al. (1996); ${ }^{7}$ Juneja et al. (2001); ${ }^{8}$ Whiting and Cygnarowicz-Provost (1992); ${ }^{9}$ Buchanan et al. (1997); ${ }^{10}$ Richards (1959); ${ }^{11}$ Schnute (1981); ${ }^{12}$ Stannard et al. (1985); ${ }^{13}$ Williams et al. (1955); ${ }^{14}$ Běhrádek (1930) ${ }^{15}$ Ratkowsky et al. (1982); ${ }^{16}$ Arrhenius (1889); ${ }^{17}$ Davey (1993); ${ }^{18}$ Hauschild (1982); ${ }^{19}$ Marini (2009) ${ }^{20}$ Juneja et al. (1997); ${ }^{21}$ Khuri (2011); ${ }^{22}$ Juneja et al. (2011); ${ }^{23}$ Lee et al. (2014); ${ }^{24}$ Ólafsdóttir et al. (2006); ${ }^{25}$ Baranyi and Tamplin (2004). 
Various secondary models have been applied to model growth and inactivation of microorganisms. These models can be simple linear regressions, or more complex polynomial models such as those based on response surface methodology that require sophisticated computational software (Khuri, 2011), squire root models (Ratkowsky et al., 1991) and Arrhenius equations. The z-value is another type of secondary model that describes the change in $D$-value as a function of temperature. Generally, lag time and growth rate have been modelled using square-root, gamma and cardinal methods. Applications comprise modelling microbial growth or inactivation interfaces, the length of the lag phase for microorganisms in formulated ready-to-eat foods, and the production of microbial toxins (Whiting, 1995). Recently, Artificial Neural Networks is also used to for modelling purposes (Marini, 2009). Some of the examples of secondary models used in the recent studies are given in Table 14.1.

Tertiary mathematical model development involves expressing secondary model predictions through a primary model. This is normally done either with commercial spreadsheets or computer software. Computer software program provides an interface between the model's mathematics and the end user, allowing the information to be entered into the model then the prediction to be viewed as a figure and tables. However, tertiary level mathematical modelling needs skilled personnel to interpret the information given by the models. The users should know the limits and condition of models application to avoid flawed predictions. There are various types of the model software packages such as a Pathogen Modelling Program (PMP), Growth Predictor, Pseudomonas Predictor which are used for the mathematical modelling. Some of the examples of tertiary models used in the recent studies are given in Table 14.1.

The Institute of Food Research, UK has produced "Growth Predictor" (http://www.ifr.ac.uk/Safety/GrowthPredictor/default.html), set of model for predicting the growth of bacteria in microbiological broth as a function of temperature, $\mathrm{pH}$, water activity, 
carbon dioxide and acetic acid. The users can also input the inoculum level and a value for the physiological state of the bacteria. These factors allow the user control over the prediction of the lag phase.

The "Pathogen Modelling Programme" was developed by the Food Safety Research Unit of the United States Department of Agriculture Research Services and can be downloaded at http://ars.usda.gov/Services/docs.htm?docid=6786. This model can be used to predict the growth, survival, inactivation and toxin production of the food-borne bacteria, primarily pathogens under various environmental conditions. This model allows users to input conditions for a variety of intrinsic and extrinsic environmental condition such as $\mathrm{pH}$, temperature, water activity, atmosphere, the concentrations of various acidulants, irradiation dose. The program contains growth models for certain bacterial strains (Clostridium perfringens, B. cereus, E. coli O157:H7, L. monocytogenes, Salmonella etc) and specific environments (culture medium, food etc.).

"Microfit software" developed by the Institute of Food Research, UK, enable the estimation of growth rate, doubling time, initial cell number and lag time from challenge test data. The software facilitates the compares individual growth curves with predictions from software packages such as Food Micro Model and the Pathogen Modelling program.

The "Seafood Spoilage and Safety Predictor" (SSSP) software package was developed as a time, temperature integration device that facilitates the use of different mathematical seafood spoilage models. The software package predicts the self-life and growth of specific spoilage organisms in seafood under constant or fluctuating temperature conditions. This software was developed at the National Institute of Aquatic Resources, Technical University of Denmark.

"ComBase" (http://www.combase.cc/index.php/en/) is an international database mainly composed of thousands of microbial growth and survival curves. It is maintained by the 
ComBase Consortium that is a collaboration between the Food Standards Agency and the Institute of Food Research (UK), and the USDA Agricultural Research Service and its Eastern Regional Research Centre (US).

SymPrevius software (http://www.symprevius.org/) was supported by the French Departments of Research and Agriculture. It is a decision-making tool intended for the food industry and its partners, consisting of growth interfaces, growth simulation, growth curve fitting, thermal destruction simulation and bacterial survival simulation. The software was developed from a database that linked food, bacteria and environmental characteristics to the incidence and the behaviour of microorganisms.

Recently, USDA Agricultural Research Service has developed a new user-friendly comprehensive data analysis tool, the Integrated Pathogen Modeling Model (IPMP 2013). This tool allows users, without detailed programming knowledge, to analyze experimental kinetic data and fit the data to known mathematical models commonly used in predictive microbiology (Huang, 2014).

\subsection{Model development}

Development and implementation of mathematical modelling, involves a series of steps such as identifying the key factors, experimental design, data collection and analysis, model validation etc.

\subsubsection{Recognising the key factors}

There are numbers of intrinsic, extrinsic and implicit factors which affects the growth and survival of the microorganism in the food. Generally intrinsic factors are the characteristics of the food itself, e.g. pH, water activity, preservatives. Extrinsic factors include the environment in which food is stored, e.g. temperature, relative humidity, gaseous atmosphere. Implicit 
factors are the characteristics of the microorganism itself and how it behaves in the existence of intrinsic and extrinsic factors. Several factors may affect the growth and survival of a microorganisms present in food and it is important to consider these factors and included in the model. The intended use of the model is the prime consideration when defining the controlling factors to be included.

\subsubsection{Experimental design}

The range of condition over which the model is to function should be distinct because empirical models should not be applied beyond the area defined by the conditions used to generate the model (BlackBurn, 2000). An experimental design is requisite in which these factors can be altered easily; though, heterogeneity of food makes their use difficult for the generation of data for modelling (Maxcy and Wallen, 1983). Generally, microbiological mediums are used since it consists of all components which can be reproducible modified in the required condition. If the model is intended for a wide range of food, then the choice of factors should be incorporated such as specific organic acid, which avoid the slower bacterial growth than the actual one (BlackBurn, 2000).

The inoculum size, microbial strain, culture condition all affects the outcome of the data and subsequent predictions. The inoculum size reflecting the microbial response, and it should be noted that large inoculum size needs higher concentration of antimicrobial agents. The standard inoculum concentration chosen by the NCCLS is $5 \times 10^{5} \mathrm{CFU} / \mathrm{ml}$ of broth medium. Changes in inoculum density as well as the absolute number (rather than concentration) of total organisms present in the test system can affect the outcome. A $5 \times 10^{5} \mathrm{CFU} / \mathrm{ml}$ inoculum provides an acceptable challenge dose for assessing the biological activity of antimicrobial agents and is large enough to provide statistically satisfactory data for determining a minimum bactericidal concentration endpoint. If the inoculum is too small, significant bacterial resistance 
may not be detected (Peterson and Shanholtzer, 1992). All strains have diverse phenotypic responses so the type of strain selection and screening need to be carried out for modelling. Microbial growth condition, storage condition, including temperature and culture medium can affect the microorganism responses, so it should be carefully selected the likely condition of organism. Furthermore, sampling time is one of the important considerations for experimental design and these should be focused around most active phase of the bacterial growth such as lag phase and log phase of the bacterial growth (BlackBurn, 2000).

\subsubsection{Data collection and analysis}

Large amounts of experimental data are required to predict the effect of preservatives on growth, survival or inactivation of microorganisms. Such data have often been generated using liquid laboratory media. Quantification of microorganisms at selected time points is usually by standard colony count methods, but recently automated methods such as absorbance or conductance measurements can be used to facilitate the generation of data in liquid media. In some of the studies, in order to convert the optical density to $\log \mathrm{CFU} \mathrm{m}{ }^{-1}$, a relationship between the optical density at $600 \mathrm{~nm}$ and viable count was established for the test bacteria (Gupta et al., 2012; Jaiswal et al., 2011a).

The next step involves mathematical analysis of data to produce a model. However, this step is largely focused on the type of model to be utilized for modelling the data. For example, in the case of Modified Gompertz, Logistic model and Baranyi model, a plot of microbial count versus time for each antimicrobial concentration was used to calculate the starting values for the parameters, $N_{0}$ and $N_{\max }$ for the models evaluated (Gupta et al., 2012). However, advancement of computational software has facilitated the implementation of complex mathematical calculations which would be less time consuming for example, Statgraphics Centurion XV (StatPoint Technologies, Inc., Warrenton, VA) or Design-Expert Software 
(Version 6.0.5, Stat-ease Inc., Minneapolis, MN, USA, 2001) which can be used to fit the data while for fitting the Baranyi model a program implemented in Microsoft Excel (DM-Fit; Institute of Food Research, Norwich, UK) can be used. The aim of the model fitting procedure is to find those values of the parameters which best describe the data by minimizing the sum of the squares of the differences between the model simulated and experimental values.

\subsubsection{Validation of mathematical models}

One of the most important aspect of model development is ensuring reliability of the models. The assessment of the reliability of mathematical models is only possible through the combination of several statistical analyses and proper investigation regarding the purposes for which the mathematical model was initially conceptualized and developed.

Fakruddin et al. (2011) suggested that two step validation of a model once it has been developed. The first step is to test its accuracy with the new experimental data and new combinations of variables to determine if the model can describe the experimental data sufficiently. This is called internal validation or 'Curve fitting'. This will allow an estimation of the goodness of fit and will show if and where additional data is needed. Complex models tend to be very specific, which can be a limitation when testing new data. The quality of fit of a mathematical model can be expressed as the determination of coefficient $\left(\mathrm{R}^{2}\right)$, which is an overall measure to evaluate the prediction obtained. The higher the value $\left(0<\mathrm{R}^{2}<1\right)$ is, the better is the prediction by the model.

The second step is to compare model predictions with microbial responses in actual foods. This is called External Validation. This will show the model's limitations and may show if additional factors must be tested and included in the model. Errors in growth or survival should always tend towards faster growth rates or better survival, respectively, to make a conservative prediction (Whiting, 1995). 
Statistical measures such as Mean square error (MSE) or Root mean square error (RMSE) is commonly used to evaluate the difference between the model estimated data and experimental data. The model with the lower value of MSE or RMSE $(0<$ MSE/RMSE) is more accurate in predicting model (Brocklehurst, 2003; Zhao et al., 2014). Mean square error (MSE) (eq. 14.12) can be defined by the following expression:

$$
M S E=\frac{\sum(\text { Predicted-observed })^{2}}{n-p}
$$

Root mean square error (RMSE) (eq.14.13) can be defined by the following expression:

$$
R M S E=\sqrt{\frac{\sum(\text { Predicted-Observed })^{2}}{n-p}}
$$

where, $n$ is the number of observations and $\mathrm{p}$ is the number of parameters to be estimated.

Some authors also suggested the application of bias and accuracy factor to validate the model (Ross, 1996). The accuracy factor indicates the average deviation between the model predictions and observed results (Brocklehurst, 2003; Neumeyer et al., 1997). The accuracy factor (eq.14.14) is defined by the following expression:

$$
\text { Accuracy factor }=10 \frac{\sum \log \left(\frac{\text { Predicted }}{\text { Observed }}\right)}{\mathrm{n}}
$$

where $\mathrm{n}$ is the number of observations; "predicted" is a parameter under consideration such as the model predicted generation time and "observed" is experimentally observed generation time or specific growth rate or lag phase. The higher the value of accuracy factor, the lower in precision is the average estimate. An accuracy factor of 2 indicates that the prediction is on average different from the observed value by a factor of 2 (Ross, 1996). 
The bias factor is used to indicate the structural deviations of a model (Zhao et al., 2014). It describes the observed values that lie above or below the line of equivalence and, if so, by how much. A bias factor >1 indicates a 'fail safe' model (Brocklehurst, 2003; Zhao et al., 2014; Zhou et al., 2008). Bias factor (eq.14.15) can be defined by the following expression:

$$
\text { Bias factor }=10 \frac{\sum \log \left(\frac{\text { obserevd }}{\text { Predicted }}\right)}{\mathrm{n}}
$$

\subsection{Modelling the effects of natural antimicrobial agents}

Generally, the models that can be used for describing the kinetics of survival curves are either empirical or based on biological assumptions (Gupta et al., 2012). Primary mathematical models such as Gompertz or modified form of Gompertz model, Logistic and/or BaranyiRoberts model are the most commonly used mathematical model to analyse the delay or inhibition of growth of the organisms (Belda-Galbis et al., 2014; Gupta et al., 2012; Jaiswal et al., 2011a; Koutsoumanis et al., 1999; Pina-Pérez et al., 2009; Tornuk et al., 2014; VelázquezNuñez et al., 2013; Yao et al., 1998). However, some authors have also used the fuzzy logic system and artificial neural network to model the antimicrobial activity of natural food preservatives (Sagdic et al., 2012).

\subsubsection{Plant extracts}

Plant extracts are rich in phenolic compounds and other secondary metabolites, and some have antimicrobial activity. In recent years, several studies were carried out to find the new source of antimicrobial agents from the plant parts which can be used as an alternative to synthetic preservatives (Jaiswal et al., 2011a; Pina-Pérez et al., 2009; Tornuk et al., 2014). Yao et al. (1998) monitored the disturbances in Proteus rettgeri growth using the acoustic wave bacterial growth sensor in the aqueous extracts of various tea samples such as green tea, Fuzhuan brick tea, Oolong tea, Kudin tea, and black tea. The Modified Gompertz model was successfully 
applied to fit the growth kinetic concentration curves of $P$. rettgeri and the kinetic parameters such as asymptote, maximum specific growth rate, lag time, and generation time, accurately estimated by using the growth response model and these kinetic parameters have been used to characterize antimicrobial properties of tea.

Jaiswal et al. (2011a) evaluated the antibacterial activity of York cabbage against several food pathogens, and the survival curve was mathematically modelled using the Baranyi model. The authors observed that cabbage extracts had an antagonizing effect on the selected food pathogens, showing a remarkable dose-response relationship with an increase in the lag phase duration and decrease in the maximum specific growth rate. Analyses of variance indicated that the maximum specific growth rate was significantly reduced with increasing extract concentration. The Baranyi model was capable of fitting the experimental data very reasonably and produced curves with an $\mathrm{R}^{2}$ value ranging from 87.5 to $99.6 \%$. Pina-Pérez et al. (2009) conducted an experiment to extend the shelf-life and enhancing the safety of liquid whole egg/skim milk mixed beverages. Antibacterial activity of cocoa powder (CocoanOX 12\% ®Natraceutical S.A., Valencia, Spain) was estimated against the Bacillus cereus, which were inoculated in skim milk and liquid whole egg/skim milk mixed beverages. The beverages were also treated with Pulsed Electric Field in the presence and absence of cocoa powder. The kinetic results were modelled with the Bigelow model, Weibull distribution function, modified Gompertz equation, and Log-logistic models. It was reported that beverages supplemented with the antimicrobial compound showed higher inactivation levels reaching a $3.30 \log _{10}$ cycle reduction as compared to Pulsed Electric Field treated sample under the same conditions. Among the model fitted the four-parameter Log-logistic model showed the best fit for all beverages. 
While estimating the inhibitory effects of bay leaf, rosemary, sage, and thyme hydrosols on the growth of Staphylococcus aureus inoculated on fresh-cut apples, Tornuk et al. (2014) modelled the bacterial growth using modified Gompertz, logistic, Richards, Stannard, and Whiting and Buchanan were applied and compared to describe the inactivation of S. aureus. Validation of mathematical models were carried out using various statistical parameters such as mean percentage error, mean bias error, root mean square error and determination of coefficient. The modified Gompertz, logistic, and Stannard models exhibited better fits than Richards and Whiting and Buchanan models regarding these statistical parameters.

In another studies, Belda-Galbis et al. (2014) estimated the antibacterial activity of Stevia rebaudiana Bertoni (Stevia) against the Listeria innocua, in a medium supplemented with a leaf infusion, a crude extract, and a purified extract and experimental data were fitted to the modified Gompertz model (Figure 14.2). Antibacterial activity of Stevia was determined based on the lag phase duration and the maximum specific growth rate reached. These authors did not observe a significant difference between the controls and samples containing the purified extract, therefore no bacteriostatic/bactericidal effect against L. innocua was documented. However, an increase in lag phase and a decrease in maximum specific growth rate were found for the crude extract and the infusion. The crude extract was able to multiply lag time by two fold. With the infusion, the lag time value was 10 times higher than the lag time value without Stevia. maximum specific growth rate was halved in both cases, both in the presence of the crude extract and in the presence of the infusion. Consequently, a statistically significant antimicrobial effect can be attributed to these Stevia extracts. 


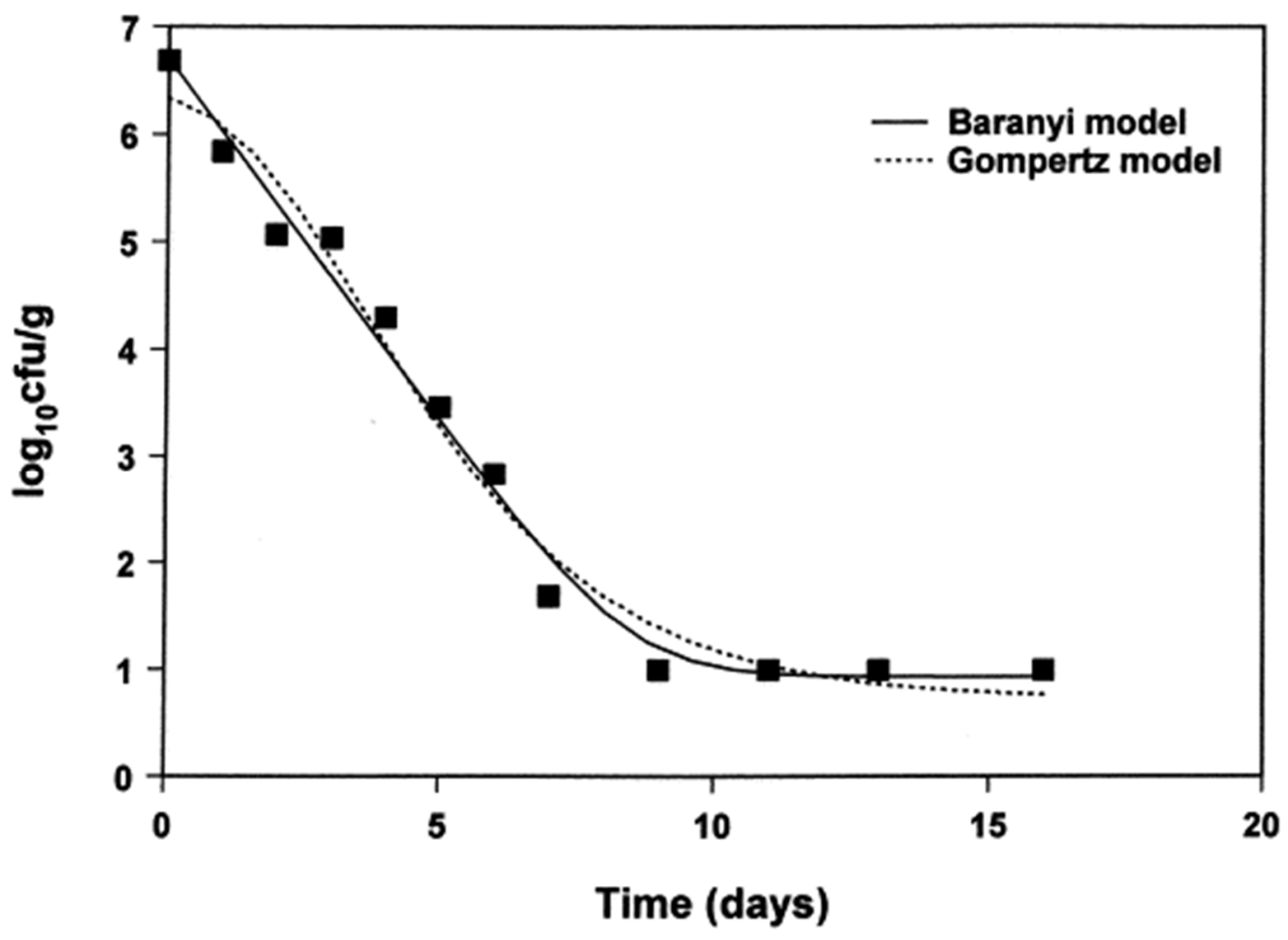

Figure 14.2. Inactivation curves for Salmonella enteritidis, fitted with the Baranyi and

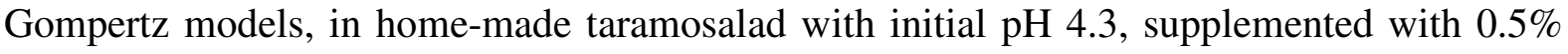
oregano essential oil and stored at $20^{\circ} \mathrm{C}$. (Adopted from Koutsoumanis et al. (1999) with permission).

\subsubsection{Essential oils}

Essential oils are aromatic oily liquids obtained from plant material such as flowers, buds, seeds, leaves, twigs, bark, herbs, wood, fruits and roots. Several studies were carried out to exploit the potential of essential oils as a source of natural antimicrobial agents. Koutsoumanis et al. (1999) estimated the effect of oregano essential oil under different temperature and $\mathrm{pH}$ profile on taramasalad, a traditional Greek appetizer against Salmonella enteritidis and at each combination of the environmental factors, the bacterial counts were modelled as a function of time in order to estimate the kinetic parameters of the S. enteritidis. Several inactivation curves representing different combinations of essential oil concentration, $\mathrm{pH}$ and storage temperature were generated using the Baranyi model and the modified Gompertz equation. While 
comparing the outputs of the two models, these authors reported that no lag phase was derived from the Baranyi model. On the contrary, the Gompertz equation gave a short lag phase in most cases (Figure 14.3). The comparative results obtained from the Baranyi and Gompertz models indicate that the Baranyi model, which is generally used for fitting growth data, may also be useful as an alternative model for describing the inactivation of bacteria under suboptimal environments such as the addition of natural antimicrobial systems. In another studies carried by Skandamis and Nychas (2000) evaluated the antibacterial activity of oregano essential oil together with different storage temperatures and pH against Escherichia coli O157:H7 NCTC 12900 in homemade eggplant salad (a traditional Greek appetizer). For each combination of the environmental factors, the bacterial counts were modelled, using the Baranyi model, as a function of time to estimate the kinetic parameters of the pathogen.
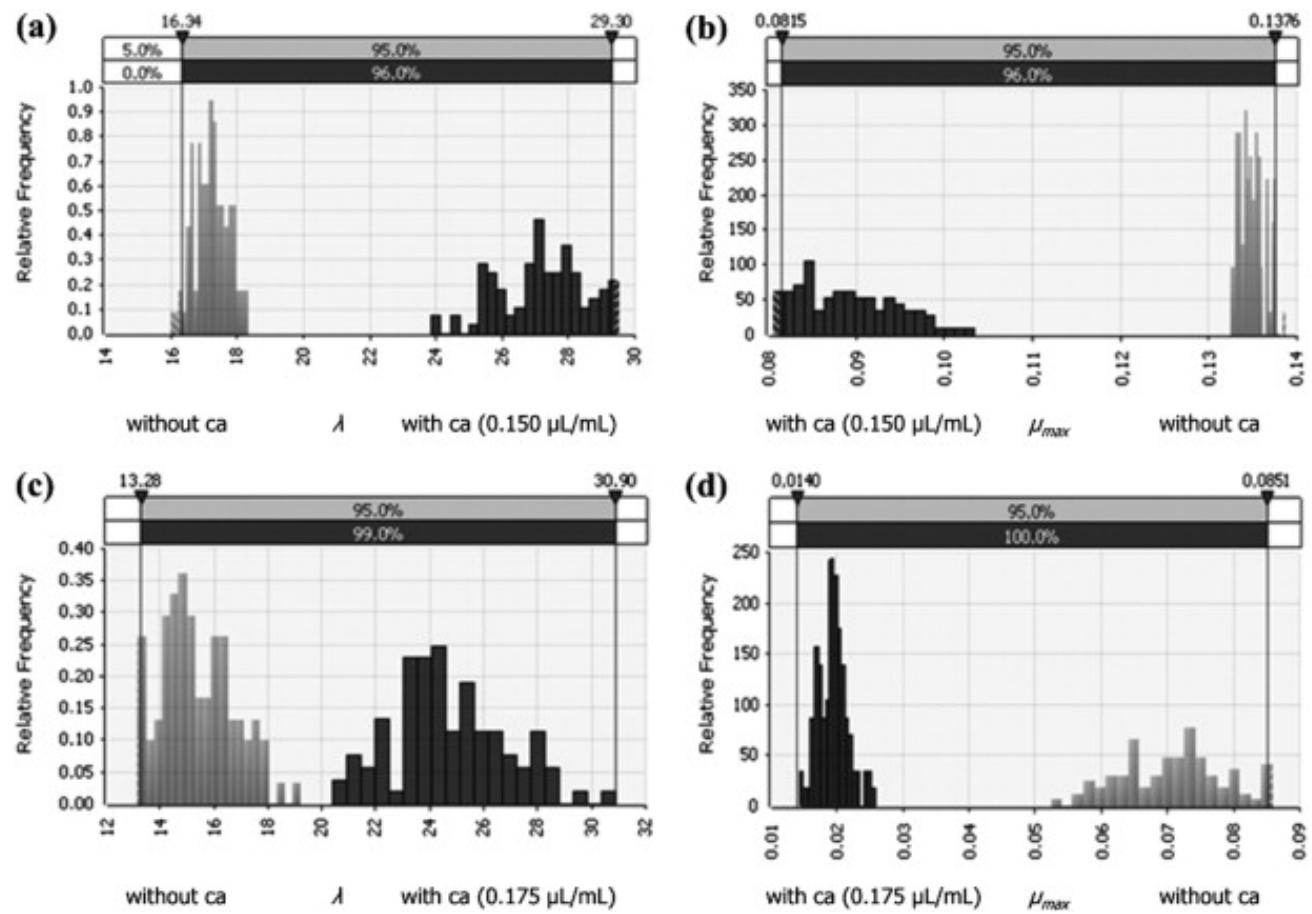

with ca $(0.175 \mu \mathrm{L} / \mathrm{mL}) \quad \mu_{\max } \quad$ without ca

Figure 14.3. Growth rate $(\mu \max ;(\log 10(\mathrm{cfu} / \mathrm{mL})) / \mathrm{h})$ and lag time $(\lambda ; \mathrm{h})$ distributions obtained from Monte Carlo simulation for Escherichia coli K12 (a-b) and Listeria innocua (cd) grown at $15^{\circ} \mathrm{C}$, with and without carvacrol (ca) (Adopted from Belda-Galbis et al. (2013) with permission). 
A similar studies were also carried out by Portillo-Ruiz et al. (2012); these authors evaluated the antifungal effect of Mexican oregano (Lippia berlandieri Schauer) essential oils fractions on the growth of Aspergillus, Penicillium, and Rhizopus sp and the growth curves were fitted using the modified Gompertz model. It was reported that Mexican oregano essential oils showed a linear reduction in specific growth rate, on the maximum mould growth at the stationary phase, and an increase in the lag time as the concentration of the oregano essential oils increased. Velázquez-Nuñez et al. (2013) compared the antifungal efficacy of orange peel essential oils, applied either by vapor exposure or direct addition on the growth of Aspergillus flavus and the radial growth rate and lag phase were calculated using the Gompertz equation. Significant differences in Modified Gompertz model parameters were observed in both the method studied. Maximum mould growth and maximum specific growth rate showed that increasing the concentration of orange peel essential oils decreases these parameters.

Belda-Galbis et al. (2013) estimated the effect of carvacrol (an important component of Oregano oil) and citral (present in the essential oils of several plants such as lemon grass) at different storage temperatures against Escherichia coli O157:H7 and Listeria monocytogenes surrogates. The results were integrated into a stochastic model to perform probabilistic predictions of the final load. The study takes into account the variability in growth conditions by means of maximum growth rate and lag time duration kinetic parameters, using the Monte Carlo simulation. It was reported that for each strain, regardless of temperature, both lag phase and maximum specific growth rate proved to be dependent on the antibacterial concentration at non-inhibitory doses. The higher the concentration, the lower the maximum specific growth rate; consequently, both, carvacrol and citral showed a bacteriostatic effect on E. coli K12 and L. innocua growth in the temperature range studied. Figure 14.4 shows the lag phase and maximum specific growth rate distributions obtained from the Monte Carlo simulation for the two bacteria, in absence and in the presence of carvacrol. As can be seen in the figure, in general 
terms, the antimicrobial addition increases the dispersion of the parameters' distributions. These results indicate that under stress conditions, such as the exposure to natural antimicrobials, enhanced the uncertainty of deterministic growth prediction results.

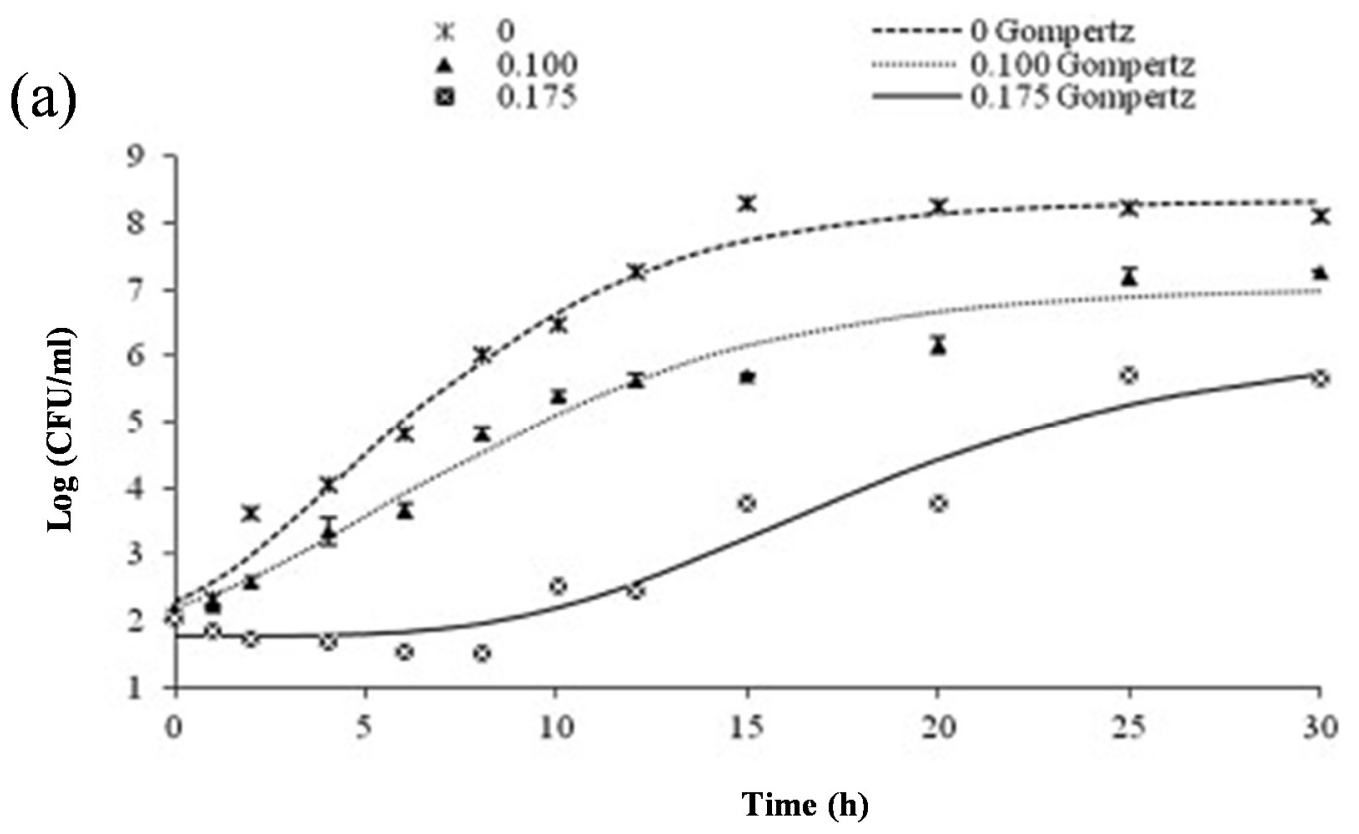

(b)

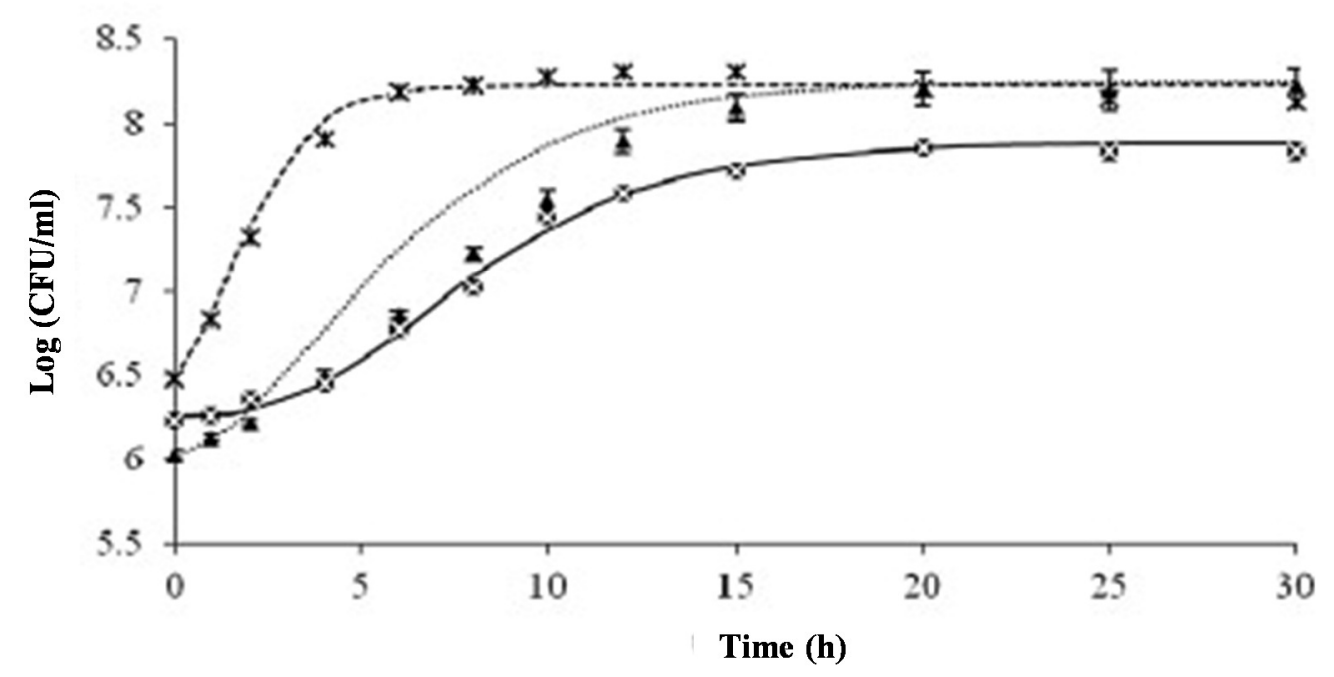

Figure 14.4. (a) L. innocua (b) L. monocytogenes growth curves in the presence of different concentrations of carvacrol $(\mu \mathrm{l} / \mathrm{ml})$ in reference medium. The lines represent the fit of experimental data to the modified Gompertz model. The standard deviation associated with each average value is expressed by error bars. 
Muñoz et al. (2010) applied a stochastic approach to evaluate the growth of heat damaged $L$. monocytogenes cells influenced by $\mathrm{pH}$ and presence of eugenol (essential oil found in cloves) using an individual-based approach of growth through OD measurements. Both the lag phase duration and the $h_{0}$ parameter were derived from the growth curves obtained. Histograms showed a shift to longer lag phases and an increase in variability with high $\mathrm{pH}$ and the presence of eugenol. The authors observed that both Monte Carlo and regression analysis gave a good indication of the probability of a certain level of growth.

\subsubsection{Seaweed extracts}

Marine macroalgae, commonly known as seaweeds, are potential renewable resource in the marine habitat. Seaweeds are rich in several secondary metabolite, such as polyphenols (phlorotannins, fucoxanthin, flavonoids) and polysaccharides (fucoidan, laminarans). Recent studies showed that it is good source of antimicrobial agent. Gupta et al. (2012) used brown seaweed extract as a natural antimicrobial agent against several bacteria and growth kinetics was modelled using Baranyi, Modified Gompertz and Logistic model for describing the survival of organisms in the presence of different concentrations of the extract. The authors observed that in most of the cases, the $\mathrm{R}^{2}$ values for all the models were greater than $90 \%$ representing a good fit to the experimental data. All the parameters obtained for the three mathematical models were directly related to the extract concentration. Analyses of variance indicated that the maximum specific growth rate was significantly reduced (99-96.8\%) while lag phase for all the three models increased (20-81\%) with the extract concentration. These authors observed that all the three models were capable of fitting the experimental data very rationally and produced almost similar curves; however, no model could produce consistently best fit to all the growth curves. The models were statistically validated with the use of $F$-test. The calculated $F$-values were lower than the $F$ Table values, indicating that there was no significant difference in the goodness of fit between the three models. 


\subsubsection{Others}

Guerrero et al. (2005) evaluate the resistance of Saccharomyces cerevisiae by the action of ultrasound at $45^{\circ} \mathrm{C}$ in Sabouraud broth containing $1000 \mathrm{ppm}$ low weight chitosan and the experimental data were modelled using the modified Gompertz equation and Weibull distribution of resistances. These authors reported that addition of chitosan enhanced the inactivation by ultrasound. Lavermicocca et al. (2003) estimated the fungicidal activity of phenyllactic acid (organic acid, produced by many microorganisms, especially lactic acid bacteria) against 23 fungal strains belonging to 14 species of Aspergillus, Penicillium, and Fusarium that were isolated from bakery products, flours, or cereals. Optical density was recorded every $24 \mathrm{~h}$ from zero time to $120 \mathrm{~h}$ were used to generate growth curves for each fungal strain and the Gompertz model was used as a mathematical means of fitting growth curves to estimate microbial growth kinetics.

In order to estimate the effect of interaction between two strains of Lactobacillus plantarum and two food-borne pathogens, Listeria monocytogenes and Escherichia coli, Aguilar et al. (2011) used whole UHT milk as experimental media at $37^{\circ} \mathrm{C}$. To determine the type of interaction between the two bacterial populations in co-cultures and to evaluate the antagonistic activity of the lactic acid bacteria on the pathogenic bacteria, the growth curves, the kinetic parameters, and the $\mathrm{pH}$ profiles of mono and co-cultures were compared. These authors reported that the lactic acid bacteria reduced the growth of $E$. coli and of L. monocytogenes by 4 and $\sim 5 \log$ cycles, respectively, and influenced other growth kinetic parameters, such as maximum specific growth rate and lag phase, in the different binary combinations. Pena and de Massaguer (2006) evaluated the adaptation time of Alicyclobacillus acidoterrestris CRA 7152 in orange juice, which was determined as a response to $\mathrm{pH}$, temperature, soluble solids, and nisin (polycyclic antibacterial peptide, produced by lactic acid bacteria, especially L. lactis) addition. Results showed that the Baranyi and Roberts model was better than the modified 
Gompertz model, considering the determination of coefficient $\left(\mathrm{R}^{2}\right)$ as a measure to evaluate the prediction obtained.

Zhou et al. (2013) evaluated the inhibition effects of vapor phase thymol, modified atmosphere, and their combination against Salmonella spp. on raw shrimp. Lag time and maximum growth rate of Salmonella spp. under each treatment were obtained using Baranyi and Roberts models. Combination treatments of vapor phase thymol and MA exhibited greater inhibition effectiveness than each individual treatment and a synergistic antimicrobial effectiveness could be observed on the lag time extension. To the maximum, at $12^{\circ} \mathrm{C}$, lag time of Salmonella spp. was extended $59.6 \%$ more by the combination treatment of $0.8 \mathrm{mg} / \mathrm{L}$ thymol + modified atmosphere $(36.97 \mathrm{~h})$ than those effects combined from $0.8 \mathrm{mg} / \mathrm{L}$ thymol treatment and MA treatment alone (23.16 $\mathrm{h}$ in total).

\subsection{Concluding remarks and Future trends}

Predictions of microbial behaviour are not $100 \%$ accurate. Variations and uncertainty are introduced through experimental error, strain variation, and other intrinsic, extrinsic and implicit factors which affect the growth and survival of the microorganism in the food. Efforts were made by mathematicians to develop new forms of model that provide more and more reliable estimates between model simulated data and experimental data. Consequently, plethora of growth models has recently been developed to model the growth, survival, inactivation or biochemical process of a foodborne organisms. However, primary mathematical models such as modified Gompertz model, Logistic and Baranyi-Roberts model is yet the most commonly used models to analyse the delay or inhibition of growth of the organisms and parameters normally include lag phase duration, growth rate and maximum population density. 
During the last few years, increased attention has been given to quality and safety of food not only because of consumer's perspective also due to governmental pressure. Recent regulations by the FDA have required processors to achieve a $5 \log$ reduction in the numbers of the most resistant pathogens in their finished products. The ruling has accelerated the search for novel processing technologies, including application of preservatives from natural origin in food that can ensure product safety, yet maintain the desired nutritional and sensory characteristics. Consequently, most models were targeted towards elimination of food pathogens in order to help ensure microbiologically safe food products and as a result, there is likely to be increased research in the area of food microbiology and the application of predictive modelling to ensure that their applied processes are up to the very highest standards.

\section{References}

Aguilar, C., Vanegas, C., Klotz, B., (2011). Antagonistic effect of Lactobacillus strains against Escherichia coli and Listeria monocytogenes in milk. Journal of Dairy Research, 78(02), 136-143.

Álvarez-Fernández, E., Cancelo, A., Díaz-Vega, C., Capita, R., Alonso-Calleja, C., (2013). Antimicrobial resistance in E. coli isolates from conventionally and organically reared poultry: A comparison of agar disc diffusion and Sensi Test Gram-negative methods. Food Control, 30(1), 227-234.

Andraud, M., Chauvin, C., Sanders, P., Laurentie, M., (2011). Pharmacodynamic modeling of in vitro activity of marbofloxacin against Escherichia coli strains. Antimicrobial Agents and Chemotherapy, 55(2), 756-761.

Arrhenius, S., (1889). About the reaction rate in the inversion of cane sugar by acids. Journal of Physical Chemistry, 4, 226-248. 
Baranyi, J., Roberts, T., McClure, P., (1993). A non-autonomous differential equation to modelbacterial growth. Food Microbiology, 10(1), 43-59.

Baranyi, J., Tamplin, M.L., (2004). ComBase: a common database on microbial responses to food environments. Journal of Food Protection®, 67(9), 1967-1971.

Běhrádek, J., (1930). Temperature coefficients in biology. Biological Reviews, 5(1), 30-58.

Belda-Galbis, C.M., Pina-Pérez, M.C., Espinosa, J., Marco-Celdrán, A., Martínez, A., Rodrigo, D., (2014). Use of the modified Gompertz equation to assess the Stevia rebaudiana Bertoni antilisterial kinetics. Food Microbiology, 38, 56-61.

Belda-Galbis, C.M., Pina-Pérez, M.C., Leufvén, A., Martínez, A., Rodrigo, D., (2013). Impact assessment of carvacrol and citral effect on Escherichia coli K12 and Listeria innocua growth. Food Control, 33(2), 536-544.

BlackBurn, C., (2000). Modelling shelf-life. The stability and shelf-life of food, 54-78.

Boekel, M.A.J.S.V., (1996). Statistical aspects of kinetic modeling for food science problems. Journal of Food Science, 61(3), 477-486.

Botterweck, A.A.M., Verhagen, H., Goldbohm, R.A., Kleinjans, J., van den Brandt, P.A., (2000). Intake of butylated hydroxyanisole and butylated hydroxytoluene and stomach cancer risk: results from analyses in the Netherlands Cohort Study. Food and Chemical Toxicology, 38(7), 599-605.

Bovill, R., Bew, J., Cook, N., D’agostino, M., Wilkinson, N., Baranyi, J., (2000). Predictions of growth for Listeria monocytogenes and Salmonella during fluctuating temperature. International Journal of Food Microbiology, 59(3), 157-165.

Brocklehurst, T., (2003). Challenge of food and the environment, in: McKellar, R.C., Lu, X. (Eds.), Modeling Microbial Responses in Food. . CRC Press.

Brul, S., Coote, P., (1999). Preservative agents in foods: Mode of action and microbial resistance mechanisms. International Journal of Food Microbiology, 50(1-2), 1-17. 
Buchanan, R., Whiting, R., Damert, W., (1997). When is simple good enough: a comparison of the Gompertz, Baranyi, and three-phase linear models for fitting bacterial growth curves. Food Microbiology, 14(4), 313-326.

Buchanan, R.L., (1993). Predictive food microbiology. Trends in Food Science \& Technology, 4(1), 6-11.

Cleveland, J., Montville, T.J., Nes, I.F., Chikindas, M.L., (2001). Bacteriocins: safe, natural antimicrobials for food preservation. International Journal of Food Microbiology, 71(1), $1-20$.

Daglia, M., (2012). Polyphenols as antimicrobial agents. Current Opinion in Biotechnology, 23(2), 174-181.

Davey, K., (1993). Linear-Arrhenius models for bacterial growth and death and vitamin denaturations. Journal of Industrial Microbiology, 12(3-5), 172-179.

Diao, W.-R., Hu, Q. P., Feng, S.-S., Li, W. Q., Xu, J.-G., (2013). Chemical composition and antibacterial activity of the essential oil from green huajiao (Zanthoxylum schinifolium) against selected foodborne pathogens. Journal of Agricultural and Food Chemistry, 61(25), 6044-6049.

Draper, N.R., (1988). Response surface designs In: Encyclopaedia of Statistical Sciences. Wiley, New York.

Fakruddin, M., Mazumdar, R.M., Mannan, K.S.B., (2011). Predictive microbiology: Modeling microbial responses in food. Ceylon Journal of Science (Biological Sciences), 40(2), 121131.

Gibson, A.M., Bratchell, N., Roberts, T., (1987). The effect of sodium chloride and temperature on the rate and extent of growth of Clostridium botulinum type A in pasteurized pork slurry. Journal of Applied Microbiology, 62(6), 479-490. 
Gibson, A.M., Hocking, A.D., (1997). Advances in the predictive modelling of fungal growth in food. Trends in Food Science \& Technology, 8(11), 353-358.

Gonzales-Barron, U.A., (2011). Predictive Microbial Modelling, in: Sun, D.-W. (Ed.), Handbook of Food Safety Engineering. Wiley-Blackwell, Oxford, UK., pp. 108-152.

Guerrero, S., Tognon, M., Alzamora, S.M., (2005). Response of Saccharomyces cerevisiae to the combined action of ultrasound and low weight chitosan. Food Control, 16(2), 131139.

Gupta, S., Cox, S., Rajauria, G., Jaiswal, A.K., Abu-Ghannam, N., (2012). Growth inhibition of common food spoilage and pathogenic microorganisms in the presence of brown seaweed extracts. Food and Bioprocess Technology, 5(5), 1907-1916.

Hauschild, A., (1982). Assessment of botulism hazards from cured meat products. Food Technology, 36(12), 95-104.

Hayes, J., Stepanyan, V., Allen, P., O’Grady, M., Kerry, J., (2010). Effect of lutein, sesamol, ellagic acid and olive leaf extract on the quality and shelf-life stability of packaged raw minced beef patties. Meat Science, 84(4), 613-620.

Holley, R.A., Patel, D., (2005). Improvement in shelf-life and safety of perishable foods by plant essential oils and smoke antimicrobials. Food Microbiology, 22(4), 273-292.

Houtsma, P., Kant-Muermans, M., Rombouts, F., Zwietering, M., (1996). Model for the combined effects of temperature, $\mathrm{pH}$, and sodium lactate on growth rates of Listeria innocua in broth and Bologna-type sausages. Applied and Environmental Microbiology, 62(5), 1616-1622.

Huang, L., (2014). IPMP 2013 - A comprehensive data analysis tool for predictive microbiology. International Journal of Food Microbiology, 171(0), 100-107. 
Isabelle, L., André, L., (2006). Quantitative prediction of microbial behaviour during food processing using an integrated modelling approach: a review. International Journal of Refrigeration, 29(6), 968-984.

Jaiswal, A.K., Gupta, S., Abu-Ghannam, N., Cox, S., (2011a). Application of Baranyi function to model the antibacterial properties of solvent extract from Irish York cabbage against food spoilage and pathogenic bacteria. Food Science and Technology International, $17(5), 495-502$.

Jaiswal, A.K., Rajauria, G., Abu-Ghannam, N., Gupta, S., (2011b). Phenolic composition, antioxidant capacity and antibacterial activity of selected Irish Brassica vegetables. Natural Product Communications, 6(9), 1299-1304.

Jaiswal, S., Varma, P., O'Neill, L., Duffy, B., McHale, P., (2013). An investigation of the biochemical properties of tetrazines as potential coating additives. Materials Science and Engineering: C., 33(4), 1925-1934.

Jason, A., (1983). A deterministic model for monophasic growth of batch cultures of bacteria. Antonie van Leeuwenhoek, 49(6), 513-536.

Jordán, M.J., Lax, V., Rota, M.C., Lorán, S., Sotomayor, J.A., (2013). Effect of bioclimatic area on the essential oil composition and antibacterial activity of Rosmarinus officinalis L. Food Control, 30(2), 463-468.

Juneja, V., Eblen, B., Ransom, G., (2001). Thermal Inactivation of Salmonella spp. in Chicken Broth, Beef, Pork, Turkey, and Chicken: Determination of D-and Z-values. Journal of Food Science, 66(1), 146-152.

Juneja, V.K., Dwivedi, H.P., Yan, X., (2012). Novel natural food antimicrobials*. Annual Review of Food Science and Technology, 3, 381-403. 
Juneja, V.K., Huang, L., Yan, X., (2011). Thermal inactivation of foodborne pathogens and the USDA pathogen modeling program. Journal of Thermal Analysis and Calorimetry, 106(1), 191-198.

Juneja, V.K., Snyder Jr, O.P., Marmer, B.S., (1997). Thermal destruction of Escherichia coli O157: H7 in beef and chicken: determination of D-and Z-values. International Journal of Food Microbiology, 35(3), 231-237.

Khuri, A.I., (2011). Response Surface Methodology, International Encyclopedia of Statistical Science. Springer, pp. 1229-1231.

Kim, S.-J., Cho, A.R., Han, J., (2013). Antioxidant and antimicrobial activities of leafy green vegetable extracts and their applications to meat product preservation. Food Control, 29(1), 112-120.

Koutsoumanis, K., Lambropoulou, K., Nychas, G., (1999). A predictive model for the nonthermal inactivation of Salmonella enteritidis in a food model system supplemented with a natural antimicrobial. International Journal of Food Microbiology, 49(1), 63-74.

Krist, K.A., Ross, T., McMeekin, T.A., (1998). Final optical density and growth rate; effects of temperature and $\mathrm{NaCl}$ differ from acidity. International Journal of Food Microbiology, 43(3), 195-203.

Lambert, R., Pearson, J., (2000). Susceptibility testing: accurate and reproducible minimum inhibitory concentration (MIC) and non-inhibitory concentration (NIC) values. Journal of Applied Microbiology, 88(5), 784-790.

Lambert, R.J.W., Lambert, R., (2003). A model for the efficacy of combined inhibitors. Journal of Applied Microbiology, 95(4), 734-743.

Lavermicocca, P., Valerio, F., Visconti, A., (2003). Antifungal activity of phenyllactic acid against molds isolated from bakery products. Applied and Environmental Microbiology, 69(1), 634-640. 
Lee, Y.J., Jung, B.S., Yoon, H.J., Kim, K.-T., Paik, H.-D., Lee, J.-Y., (2014). Predictive model for the growth kinetics of Listeria monocytogenes in raw pork meat as a function of temperature. Food Control, 44, 16-21.

Marini, F., (2009). Artificial neural networks in foodstuff analyses: Trends and perspectives A review. Analytica Chimica Acta, 635(2), 121-131.

Maxcy, R., Wallen, S., (1983). Heterogeneity of samples as a problem in shelf-life prediction. Journal of Food Protection, 46, 542-544.

McDonald, K., Sun, D.-W., (1999). Predictive food microbiology for the meat industry: a review. International Journal of Food Microbiology, 52(1), 1-27.

McMeekin, T.A., Olley, J., Ross, T., (1993). Predictive microbiology: theory and application. Research studies press., Taunton, UK.

Monod, J., (1949). The growth of bacterial cultures. Annual Reviews in Microbiology, 3(1), 371-394.

Mueller, M., de la Peña, A., Derendorf, H., (2004). Issues in pharmacokinetics and pharmacodynamics of anti-infective agents: kill curves versus MIC. Antimicrobial Agents and Chemotherapy, 48(2), 369-377.

Muñoz, M., Guevara, L., Palop, A., Fernández, P.S., (2010). Prediction of time to growth of Listeria monocytogenes using Monte Carlo simulation or regression analysis, influenced by sublethal heat and recovery conditions. Food Microbiology, 27(4), 468-475.

Neumeyer, K., Ross, T., Thomson, G., McMeekin, T., (1997). Validation of a model describing the effects of temperature and water activity on the growth of psychrotrophic pseudomonads. International Journal of Food Microbiology, 38(1), 55-63.

Ólafsdóttir, G., Lauzon, H., Martinsdottir, E., Kristbergsson, K., (2006). Influence of storage temperature on microbial spoilage characteristics of haddock fillets (Melanogrammus 
aeglefinus) evaluated by multivariate quality prediction. International Journal of Food Microbiology, 111(2), 112-125.

Pena, W.E.L., de Massaguer, P.R., (2006). Microbial modeling of Alicyclobacillus acidoterrestris CRA 7152 growth in orange juice with nisin added. Journal of Food Protection®, 69(8), 1904-1912.

Peterson, L., Shanholtzer, C., (1992). Tests for bactericidal effects of antimicrobial agents: technical performance and clinical relevance. Clinical Microbiology Reviews, 5(4), 420432.

Pina-Pérez, M., Silva-Angulo, A., Rodrigo, D., Martínez-López, A., (2009). Synergistic effect of Pulsed Electric Fields and CocoanOX 12\% on the inactivation kinetics of Bacillus cereus in a mixed beverage of liquid whole egg and skim milk. International Journal of Food Microbiology, 130(3), 196-204.

Portillo-Ruiz, M.C., Sánchez, R.A.-S., Ramos, S.V., Muñoz, J.V.T., Nevárez-Moorillón, G.V., (2012). Antifungal effect of Mexican oregano (Lippia berlandieri Schauer) essential oil on a wheat flour-based medium. Journal of Food Science, 77(8), M441-M445.

Ratkowsky, D., Olley, J., McMeekin, T., Ball, A., (1982). Relationship between temperature and growth rate of bacterial cultures. Journal of Bacteriology, 149(1), 1-5.

Ratkowsky, D., Ross, T., McMeekin, T., Olley, J., (1991). Comparison of Arrhenius-type and Bêlehrádek-type models for prediction of bacterial growth in foods. Journal of Applied Microbiology, 71(5), 452-459.

Richards, F., (1959). A flexible growth function for empirical use. Journal of experimental Botany, 10(2), 290-301.

Roberts, T., (1989). Combinations of antimicrobials and processing methods. Food technology, 43, 156-163. 
Ross, T., (1996). Indices for performance evaluation of predictive models in food microbiology. Journal of Applied Microbiology, 81(5), 501-508.

Ross, T., McMeekin, T., (1995). Predictive microbiology and HACCP, in: Pearson, A.M.D., T.R. (Ed.), HACCP in Meat, Poultry, and Fish Processing. Springer, pp. 330-357.

Sagdic, O., Ozturk, I., Kisi, O., (2012). Modeling antimicrobial effect of different grape pomace and extracts on $S$. aureus and $E$. coli in vegetable soup using artificial neural network and fuzzy logic system. Expert Systems with Applications, 39(8), 6792-6798.

Schnute, J., (1981). A versatile growth model with statistically stable parameters. Canadian Journal of Fisheries and Aquatic Sciences, 38(9), 1128-1140.

Skandamis, P.N., Nychas, G.-J.E., (2000). Development and evaluation of a model predicting the survival of Escherichia coli O157: H7 NCTC 12900 in homemade eggplant salad at various temperatures, $\mathrm{pHs}$, and oregano essential oil concentrations. Applied and Environmental Microbiology, 66(4), 1646-1653.

Solórzano-Santos, F., Miranda-Novales, M.G., (2012). Essential oils from aromatic herbs as antimicrobial agents. Current Opinion in Biotechnology, 23(2), 136-141.

Stannard, C.J., Williams, A.P., Gibbs, P.A., (1985). Temperature/growth relationships for psychrotrophic food-spoilage bacteria. Food Microbiology, 2(2), 115-122.

Tiwari, B.K., Valdramidis, V.P., O’Donnell, C.P., Muthukumarappan, K., Bourke, P., Cullen, P., (2009). Application of natural antimicrobials for food preservation. Journal of Agricultural and Food Chemistry, 57(14), 5987-6000.

Tornuk, F., Ozturk, I., Sagdic, O., Yilmaz, A., Erkmen, O., (2014). Application of predictive inactivation models to evaluate survival of Staphylococcus aureus in fresh-cut apples treated with different plant hydrosols. International Journal of Food Properties, 17(3), 587-598. 
Van Impe, J., Nicolaï, B.M., Martens, T., De Baerdemaeker, J., Vandewalle, J., (1992). Dynamic mathematical model to predict microbial growth and inactivation during food processing. Applied and Environmental Microbiology, 58(9), 2901-2909.

Van Impe, J.F., Nicolaï, B.M., Schellekens, M., Martens, T., De Baerdemaeker, J., (1995). Predictive microbiology in a dynamic environment: a system theory approach. International Journal of Food Microbiology, 25(3), 227-249.

Vásconez, M.B., Flores, S.K., Campos, C.A., Alvarado, J., Gerschenson, L.N., (2009). Antimicrobial activity and physical properties of chitosan-tapioca starch based edible films and coatings. Food Research International, 42(7), 762-769.

Velázquez-Nuñez, M.J., Avila-Sosa, R., Palou, E., López-Malo, A., (2013). Antifungal activity of orange (Citrus sinensis var. Valencia) peel essential oil applied by direct addition or vapor contact. Food Control, 31(1), 1-4.

Whiting, R., Buchanan, R., (1993). A classification of models in predictive microbiologyreply. Food Microbiology, 10(2), 175-177.

Whiting, R., Buchanan, R., (1994). Scientific status summary: microbial modeling. Food Technology (USA).

Whiting, R., Cygnarowicz-Provost, M., (1992). A quantitative model for bacterial growth and decline. Food Microbiology, 9(4), 269-277.

Whiting, R.C., (1995). Microbial modeling in foods. Critical Reviews in Food Science \& Nutrition, 35(6), 467-494.

Williams, M.L., Landel, R.F., Ferry, J.D., (1955). The temperature dependence of relaxation mechanisms in amorphous polymers and other glass-forming liquids. Journal of the American Chemical Society, 77(14), 3701-3707.

Xiong, R., Xie, G., Edmondson, A., Sheard, M., (1999). A mathematical model for bacterial inactivation. International Journal of Food Microbiology, 46(1), 45-55. 
Yao, S., Tan, H., Zhang, H., Su, X., Wei, W., (1998). Bulk acoustic wave bacterial growth sensor applied to analysis of antimicrobial properties of tea. Biotechnology Progress, 14(4), 639-644.

Zhao, J., Gao, J., Chen, F., Ren, F., Dai, R., Liu, Y., Li, X., (2014). Modeling and predicting the effect of temperature on the growth of Proteus mirabilis in chicken. Journal of Microbiological Methods, 99(0), 38-43.

Zhou, K., Cui, T., Li, P., Liang, N., Liu, S., Ma, C., Peng, Z., (2008). Modelling and predicting the effect of temperature, water activity and $\mathrm{pH}$ on growth of Streptococcus iniae in Tilapia. Journal of Applied Microbiology, 105(6), 1956-1965.

Zhou, S., Sheen, S., Pang, Y.H., Liu, L., Yam, K.L., (2013). Antimicrobial effects of vapor phase thymol, modified atmosphere, and their combination against Salmonella spp. on raw shrimp. Journal of Food Science, 78(5), M725-M730.

Zwietering, M., Jongenburger, I., Rombouts, F., Van't Riet, K., (1990). Modeling of the bacterial growth curve. Applied and Environmental Microbiology, 56(6), 1875-1881.

Zwietering, M., Rombouts, F., Van'T Riet, K., (1993). Some aspects of modelling microbial quality of food. Food Control, 4(2), 89-96. 